\title{
Studies on Different Temperature Humidity Index Models in Relation with Production Traits for HF × GIR Halfbreds
}

\author{
Ghoshita Suryakant Hingonekar*, Dilip Kundalik Deokar, Swapnali Uttamrao Rokade \\ and Harshavardhan Shahaji Sonawane
}
Department of Animal Husbandry and Dairy Science, College of Agriculture, Dhule, Mahatma PhuleKrishiVidyapeeth, Rahuri, India

*Corresponding author

\section{A B S T R A C T}

Keywords

$\mathrm{HF} \times$ Girhalfbreds, TMY, LL, DP, PMY, THI

\section{Article Info}

Accepted: 04 December 2020 Available Online: 10 January 2021
The data on production performance of $\mathrm{HF} \times$ Girhalfbreds maintained at Research cum Development Project on Cattle (RCDP), Mahatma Phule Krishi Vidyapeeth, Rahuri district, Ahmednagar, (M.H) were utilized for present study. The least squares means of total milk yield (kg), lactation length (days), dry period (days) and peak milk yield (kg) were estimated by considering the effects of period of calving, season of calving and lactation order as non-genetic factors. Then data were corrected for significant non genetic factor effect and effect of THI was estimated. Then data were corrected for significant non genetic factor effect and effect of THI was estimated. The THI had significant influence on production traits TMY and PMY, indicating that the HF $\times$ Girhalfbreds were acclimitised to the local climate due to optimum feeding with sound management are provided. However, the THI had non-significant influence on trait LL and DP.

\section{Introduction}

The THI was extensively used in hot region all over the world to evaluate the effect of heat stress on dairy cows. It is currently used to estimate cooling necessity of dairy cattle in order to improve the efficiency of management strategies to alleviate the negative effect of heat stress. Increased pressure for intensified milk production and simultaneous rise in environmental temperature due to global warming has increased the thermal load on dairy animals. Elevated environmental temperature combined with high humidity causes discomfort and escalates the stress level in animals which is reflected in terms of reduced physiological and metabolic activities that results in reduced growth, drop in production and reproduction in farm animals. Heat stress is one of the most vital environmental stressor that has negative impact on milk yield, milk composition (fat $\%, \mathrm{SNF} \%$, protein \% etc). Construction of Temperature Humidity Index (THI) by combining several climatological parameters like dry bulb, wet bulb temperature along with relative humidity to quantify the thermal stress is one of the best method to assess heat stress on animals. Several research workers have reported that 
there exists a threshold THI value, above which the negative effects of heat stress is observed on animals. Mitigation strategies to combat heat stress includes selection of heat tolerant animals and their breeding, inclusion of heat tolerance as a trait while constructing selection index, providing balanced nutrition to the animals and implementation of good ventilation along with suitable cooling system in the farm (Behera et al., 2020).

\section{Materials and Methods}

The data of $\mathrm{HF} \times$ Girhalfbreds maintained at Research Cum-Development Project on Cattle, M.P.K.V., Rahuri for a period from 2009 to 2019 (10 years) were collected for present investigation for following Traits: a) Productive traits:1) Total lactation milk yield $(\mathrm{kg}), 2)$ Lactation length (days),3) Dry period (days),4) Peak milk yield (kg).To examine the Production traits, the research data was classified into 3 periods of calving viz. $\mathrm{P}_{1}$ (2009-2011), $\quad \mathrm{P}_{2}$ (2012-2014), $\quad \mathrm{P}_{3} \quad$ (2015 above); 3 seasons of calving, viz. $\mathrm{S}_{1}$ (Rainy) June- September, $\mathrm{S}_{2}$ (Winter) OctoberJanuary and $\mathrm{S}_{3}$ (Summer) February-May; 5 order of lactation viz. $\mathrm{L}_{1}$ first lactation, $\mathrm{L}_{2}$ second lactation, $\mathrm{L}_{3}$ third lactation, $\mathrm{L}_{4}$ fourth lactation, $\mathrm{L}_{5}$ fifth lactation; The effects of nongenetic factors like period of calving, season of calving and parity were estimated by using least-square analysis as suggested by Harvey (1990). The model was used with the assumption that different components being fitted into the model were as linear, independent and additive.

The model used was as follows:

\section{Model I}

$Y_{i j k l}=\mu+A_{i}+B_{j}+C_{k}+e_{i j k l}$

where $Y_{i j k l}$, observation of $1^{\text {th }}$ animal, $k^{\text {th }}$ parity, $\mathrm{j}^{\text {th }}$ season of calving, $\mathrm{i}^{\text {th }}$ period of calving; $\mu$ overall mean, $A_{i}$ fixed effect of $i^{\text {th }}$ period of calving ( 1 to 3 ), $B_{j}$ fixed effect of $j^{\text {th }}$ season of calving (1 to 3 ), $C_{k}$ fixed effect of $\mathrm{k}^{\text {th }}$ parity ( 1 to 5$) ; \mathrm{e}_{\mathrm{ijk}}$ random error $\sim$ NID $(0$, $\left.\sigma^{2} \mathrm{e}\right)$.

\section{Correction of data}

Whenever the effects found significant data were corrected and used for further analysis.

The data on different production traits were corrected for the significant effects of period of calving, season of calving and lactation order. The corrected data were used to find out the effect of THI on production traits.

\section{Temperature humidity index models}

Seven reported THI models were used to compute temperature humidity index as follows:

\section{THI models Reference}

THI1 $=[0.4 \times(\mathrm{Tdb}+\mathrm{Twb})] \times 1.8+32+15$ Thom(1959)

THI $=(0.35 \times \mathrm{Tdb}+0.65 \times \mathrm{Twb}) \times 1.8+32$ Bianca (1962)

THI3 $=(0.15 \times \mathrm{Tdb}+0.85 \times \mathrm{Twb}) \times 1.8+32$ Bianca (1962)

THI4 $=(\mathrm{Tdb}+\mathrm{Twb}) \times 0.72+40.6 \mathrm{NRC}$ (1971)

THI5 $=(0.55 \times \mathrm{Tdb}+0.2 \times \mathrm{Tdp}) \times 1.8+32$ +17.5 NRC (1971)

THI6 $=(1.8 \times \mathrm{Tdb}+32)-(0.55-0.0055 \times$ $\mathrm{RH}) \times(1.8 \times \mathrm{Tdb}-26.8) \mathrm{NRC}(1971)$

THI7 $=(0.8 \times \mathrm{Tdb})+[(\mathrm{RH} / 100) \times(\mathrm{Tdb}-$ 14.4)] + 46.4 (Mader et al., 2006) 
Tdb: dry bulb temperature; Twb: wet bulb temperature; RH: relative humidity; Tdp: dew point temperature. Tdb, Twb and Tdp were measured in ${ }^{\circ} \mathrm{C}$ and $\mathrm{RH}$ was measured in $\%$.

Monthly THI was computed using the environmental parameters and effect of THI was seen on traits under study by using following model.

\section{Model II}

$Y_{i j}=\mu+T_{H}+e_{i j}$

$Y_{i j} \quad-$ Observation on $j^{\text {th }}$ parameters for $i^{\text {th }}$ THI value range

$\mu$ - Overall mean

$\mathrm{THI}_{\mathrm{i}} \quad$ - Effect of $\mathrm{i}^{\text {th }} \mathrm{THI}$ value range

$\mathrm{e}_{\mathrm{ij}}{ }_{\left(0, \sigma^{2} \mathrm{e}\right)}^{- \text {Random error associated with NID }}$

7 different THI values as THI1 in 6 Ranges THI11 (71-74), THI12(74-77), THI13 (7780), THI14 (80-83), THI15 (83-86), THI6 (86-89); THI2 in 5 Ranges THI21 (60-64), THI22 (64-68), THI23 (68-72), THI24 (7276), THI25 (76 -80); THI3 in 5 Ranges THI31 (58-62), THI32 (62-66), THI33 (66-70), THI34 (70-74), THI35 (74 -78); THI4 in 4 Ranges THI41 (65-69), THI42 (69-73), THI43 (73-77), THI44 (77-81); THI5 in 6 Ranges THI51 (72-75), THI52 (75-78), THI53 (78-81), THI54 (81-84), THI55 (8487), THI56 (87 -90); THI6 in 4 Ranges THI61 (65-70), THI62 (70-75), THI63 (75-80), THI64 (80-85); THI7 in 4 Ranges THI71 (6569), THI72 (69-73), THI73 (73-77), THI74 (77-81).

\section{Duncan's Multiple Range Test (DMRT)}

Duncan's Multiple Range Test as modified by Kramer (1957) was used to make pair wise comparison among the least square means with the use of inverse elements and root mean squares for error.

If the values:-

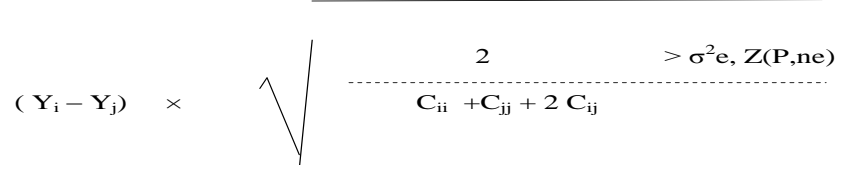

Where,

$Y_{i}-Y_{j}$ : Difference between two least squares means

$\mathrm{C}_{\mathrm{ii}}$ : Corresponding $\mathrm{i}^{\text {th }}$ diagonal elements of $\mathrm{C}$ matrix

$\mathrm{C}_{\mathrm{jj}}$ : Corresponding $\mathrm{j}^{\text {th }}$ diagonal elements of $\mathrm{C}$ matrix

$\mathrm{Z}$ ( $\mathrm{P}$, ne): Standardized range value in Duncan's table at the chosen level of probability for the error degrees of freedom

P: Number of means involved in the comparison

$\sigma^{2} \mathrm{e}:$ Root mean squares for error

\section{Results and Discussion}

\section{Effect of THI on total milk yield}

The overall least squares mean of total milk yield in $\mathrm{HF} \times$ Girhalfbreds was $2612.89 \pm$ $95.51 \mathrm{~kg}$. According to the above investigation the effect of THI7 on total milk yield of $\mathrm{HF} \times$ Girhalfbreds was significant. The differences in the total milk yield of HF $\times$ Girhalfbreds in THI 71 significantly higher than THI 72, THI 74 and THI 73.The differences in the total milk yield of $\mathrm{HF} \times$ Girhalfbreds in THI 72, THI74 and THI 73 were at par to each other (Table 1). 
Table.1 Least Square means of TMY, LL, DP and PMY in HF $\times$ Girhalfbreds

\begin{tabular}{|c|c|c|c|c|c|}
\hline \multirow[t]{2}{*}{ Effect } & \multirow[t]{2}{*}{$\mathbf{N}$} & \multicolumn{4}{|c|}{ LEAST SQUARE MEANS } \\
\hline & & Total Milk Yield & Lactation Length & Dry period & Peak milk yield \\
\hline $\boldsymbol{\mu}$ & & $2612.89 \pm 95.51$ & $280.13 \pm 6.58$ & $155.58 \pm 9.74$ & $15.80 \pm 0.40$ \\
\hline THI11 & 9 & $2561.20 \pm 330.16$ & $284.11 \pm 22.75$ & $110.55 \pm 33.70$ & $15.60^{\mathrm{bc}} \pm 1.40$ \\
\hline THI12 & 27 & $3131.56 \pm 190.62$ & $296.70 \pm 13.13$ & $146.22 \pm 19.45$ & $16.77^{\mathrm{a}} \pm 0.81$ \\
\hline THI13 & 32 & $2641.57 \pm 175.09$ & $283.43 \pm 12.06$ & $146.93 \pm 17.87$ & $16.50^{\mathrm{ab}} \pm 0.74$ \\
\hline THI14 & 52 & $2380.86 \pm 137.35$ & $293.57 \pm 9.46$ & $136.36 \pm 14.02$ & $14.05^{d} \pm 0.58$ \\
\hline THI15 & 40 & $2551.16 \pm 156.61$ & $275.17 \pm 10.79$ & $153.52 \pm 15.98$ & $16.47^{b} \pm 0.66$ \\
\hline THI16 & 9 & $2411.02 \pm 330.16$ & $247.77 \pm 22.75$ & $239.88 \pm 33.70$ & $15.44^{\mathrm{c}} \pm 1.40$ \\
\hline THI21 & 10 & $2746.28 \pm 317.52$ & $288.20 \pm 21.46$ & $105.50 \pm 31.97$ & $16.20 \pm 1.36$ \\
\hline THI22 & 34 & $2921.82 \pm 172.20$ & $290.97 \pm 11.64$ & $154.61 \pm 17.33$ & $16.55 \pm 0.73$ \\
\hline THI23 & 31 & $2566.78 \pm 180.34$ & $279.12 \pm 12.19$ & $147.00 \pm 18.15$ & $15.92 \pm 0.77$ \\
\hline THI24 & 62 & $2506.01 \pm 127.52$ & $296.00 \pm 8.62$ & $131.58 \pm 12.83$ & $14.90 \pm 0.54$ \\
\hline THI25 & 32 & $2435.50 \pm 177.50$ & $261.28 \pm 12.00$ & $187.78 \pm 17.87$ & $15.84 \pm 0.76$ \\
\hline THI31 & 15 & $2861.71 \pm 259.74$ & $290.00 \pm 17.71$ & $120.20 \pm 26.48$ & $16.72 \pm 1.11$ \\
\hline THI32 & 49 & $2600.58 \pm 143.71$ & $280.49 \pm 9.80$ & $155.91 \pm 14.65$ & $15.76 \pm 0.61$ \\
\hline THI33 & 24 & $2855.10 \pm 205.34$ & $289.91 \pm 14.00$ & $133.50 \pm 20.94$ & $16.74 \pm 0.88$ \\
\hline THI34 & 59 & $2539.01 \pm 130.97$ & $291.62 \pm 8.93$ & $144.49 \pm 13.35$ & $15.06 \pm 0.56$ \\
\hline THI35 & 22 & $2318.42 \pm 214.48$ & $267.40 \pm 14.63$ & $175.63 \pm 21.87$ & $15.27 \pm 0.91$ \\
\hline THI41 & 18 & $3079.85 \pm 234.64$ & $284.88 \pm 15.95$ & $139.05 \pm 23.95$ & $17.75 \pm 1.00$ \\
\hline THI42 & 48 & $2728.68 \pm 143.69$ & $289.16 \pm 9.76$ & $137.58 \pm 14.67$ & $16.07 \pm 0.61$ \\
\hline THI43 & 68 & $2466.19 \pm 120.72$ & $294.38 \pm 8.20$ & $139.27 \pm 12.32$ & $14.83 \pm 0.51$ \\
\hline THI44 & 35 & $2444.81 \pm 168.27$ & $260.42 \pm 11.43$ & $184.51 \pm 17.18$ & $15.70 \pm 0.71$ \\
\hline THI51 & 9 & $2561.20 \pm 331.68$ & $284.11 \pm 22.62$ & $110.55 \pm 33.82$ & $15.60 \pm 1.42$ \\
\hline THI52 & 27 & $3131.56 \pm 191.49$ & $296.70 \pm 13.06$ & $146.22 \pm 19.52$ & $16.77 \pm 0.82$ \\
\hline THI53 & 37 & $2520.26 \pm 163.58$ & $279.27 \pm 11.15$ & $153.91 \pm 16.68$ & $15.91 \pm 0.70$ \\
\hline THI54 & 52 & $2483.22 \pm 137.98$ & $298.80 \pm 9.41$ & $130.92 \pm 14.07$ & $14.55 \pm 0.59$ \\
\hline THI55 & 34 & $2511.08 \pm 170.65$ & $269.67 \pm 11.63$ & $158.47 \pm 17.40$ & $16.41 \pm 0.73$ \\
\hline THI56 & 10 & $2432.68 \pm 314.66$ & $253.30 \pm 21.46$ & $220.20 \pm 32.08$ & $15.30 \pm 1.35$ \\
\hline THI61 & 23 & $3135.92 \pm 207.07$ & $289.82 \pm 14.27$ & $131.47 \pm 21.09$ & $17.13 \pm 0.89$ \\
\hline THI62 & 51 & $2564.40 \pm 139.05$ & $286.49 \pm 9.58$ & $150.11 \pm 14.16$ & $15.59 \pm 0.60$ \\
\hline THI63 & 88 & $2497.54 \pm 105.86$ & $285.52 \pm 7.29$ & $143.60 \pm 10.78$ & $15.32 \pm 0.45$ \\
\hline THI64 & 7 & $2427.02 \pm 375.34$ & $248.28 \pm 25.87$ & $245.57 \pm 38.23$ & $15.94 \pm 1.62$ \\
\hline THI71 & 15 & $3012.69^{a} \pm 255.13$ & $284.53 \pm 17.56$ & $132.26 \pm 26.44$ & $17.36^{\mathrm{a}} \pm 1.09$ \\
\hline THI72 & 41 & $2897.63^{b} \pm 154.32$ & $297.43 \pm 10.62$ & $141.00 \pm 15.99$ & $16.36^{b} \pm 0.66$ \\
\hline THI73 & 68 & $2395.66^{b c} \pm 119.82$ & $288.39 \pm 8.25$ & $140.83 \pm 12.41$ & $14.54^{c} \pm 0.51$ \\
\hline THI74 & 45 & $2506.34^{c} \pm 147.30$ & $268.15 \pm 10.14$ & $170.97 \pm 15.26$ & $16.20^{b c} \pm 0.63$ \\
\hline
\end{tabular}

The maximum total milk yield in THI7, within range 1 i.e., THI71 (3012.69 \pm 255.13$)$ and minimum total milk yield in THI 73 (2395.66 \pm 119.82$)$. This results was in accordance with Ghavi Hossein-Zadeh et al., (2012), V. Gantner et al., (2012), H. Hammami et al., (2013), ForoughZareTamami et al.(2017), Behera et al., (2017), Habeeb, (2020) in dairy cows.

\section{Effect of THI on Lactation Length}

The overall least squares mean of total milk yield in $\mathrm{HF} \times$ Girhalfbreds was $280.13 \pm 6.58$ days.

According to the above investigation the effect of none of the THI was significant on lactation length of $\mathrm{HF} \times$ Girhalfbreds. This results was in accordance with Ghavi 
Hossein-Zadeh et al., (2012), V. Gantner et al., (2012), H. Hammami et al., (2013), ForoughZare-Tamami et al., (2017), Behera et al., (2017), Habeeb, (2020) in dairy cows.

\section{Effect of THI on Dry Period}

The overall least squares mean of dry period in $\mathrm{HF} \times$ Girhalfbreds was $155.58 \pm 9.74$ days. According to the above investigation the effect of none of the THI was significant on dry period of $\mathrm{HF} \times$ Girhalfbreds. This results was in accordance with Ghavi Hossein-Zadeh et al., (2012), V. Gantner et al., (2012), H. Hammami et al., (2013), Forough ZareTamami et al.(2017) in dairy cows.

\section{Effect of THI on Peak Milk Yield}

The overall least squares mean of peak milk yield in $\mathrm{HF} \times$ Girhalfbreds was $15.80 \pm 0.40$ $\mathrm{kg}$. According to the above investigation the effect of THI1 and THI7 on peak milk yield of $\mathrm{HF} \times$ Girhalfbreds, was significant. The differences in the peak milk yield of cows in THI 12 significantly higher than THI13, THI 15, THI 11, THI 16 and THI 14 were at par to each other and THI71 significantly higher than THI72, THI74 and THI73 were at par each other. The maximum monthly milk yield first in THI1, within range 2 i.e., THI 12 $(16.77 \pm 0.81)$ and in THI7, within range 1 i.e., THI71(17.36 \pm 1.09$)$ and minimum monthly milk yield first in THI 14 (14.05 \pm 0.58 ) and in THI7,within range 3 i.e., THI73 (14.54 \pm 0.51$)$. This results was in accordance with GhaviHossein-Zadeh et al., (2012), Gantner et al., (2012), Behera et al., (2017) in dairy cows.

\section{References}

Behera R., Chakravarty A.K., Sahu A., Kashyap N., Rai S. and Mandal A. (2017). Identification of best temperature humidity index model for assessing impact of heat stress on milk constituent traits in Murrah buffaloes under subtropical climatic conditions of Northern India. Indian J. Anim. Res., 52(1): 13-19.

Behera R., Mandal A., Rai S., Karunakaran M. and Mondal M. (2020). Temperature Humidity Index and its relationship with production traits of dairy cattle and buffaloes - Review. International Journal of Livestock Research 10(3):38-48.

Forough Zare-Tamami, HasanHafezian, Ghodrat Rahimi-Mianji, Rohullah Abdullahpour, and Mohsen Gholizadeh (2017). Effect of the temperature-humidity index and lactation stage on milk production traits and somatic cell score of dairy cows in Iran.Songklanakarin J. Sci. Technol. 40 (2), 379-383.

Gantner, P. Mijic, S. Jovanovac, N. Raguz, T. Bobic and Kuterovac, K. (2012). Influence of temperature-humidity index (THI) on daily production of dairy cows in Mediterranean region in Croatia. Article in EAAP Scientific Series, January 2012. 131(1): 71-80.

GhaviHossein-Zadeh, N., Mohit, A. and Azad, N. (2012). Effect of temperature-humidity index on productive and reproductive performances of Iranian Holstein cows. Iranian Journal of Veterinary Research, Shiraz University, 2013, 14(2): 106-112.

Habeeb, A. A. (2020). Impact of climate change in relation to TemperatureHumidity Index on productive and reproductive efficiency of dairy cattle. Int J Vet Anim Med 3(1):1-10.

Hammami, H., J. Bormann, N. M'hamdi, H. H. Montaldo and Gengler, N. (2013). Evaluation of heat stress effects on production traits and somatic cell score of Holsteins in a temperate 
environment. J. Dairy Sci. 96: 18441855.

Harvey W.R. (1990). Least-squares analysis of data with unequal subclass numbers. ARS H-4, U.S.D.A,
Washington.

Kramer, C.V. (1957). Extension of multiple range test to group correlated adjusted mean. Biometrics, 13: 13-20.

\section{How to cite this article:}

Ghoshita Suryakant Hingonekar, Dilip Kundalik Deokar, Swapnali Uttamrao Rokade and Harshavardhan Shahaji Sonawane. 2021. Studies on Different Temperature Humidity Index Models in Relation with Production Traits for $\mathrm{HF} \times$ GIR Halfbreds. Int.J.Curr.Microbiol.App.Sci. 10(01): 172-177. doi: https://doi.org/10.20546/ijcmas.2021.1001.020 